\section{BMJ Open Respiratory Research}

\title{
Secondary erythrocytosis following drugs used in rifampicin/multidrug- resistant tuberculosis: a retrospective cohort study
}

\author{
Sirak Tesfamariam (10 , ${ }^{1}$ Amon Solomon Ghebrenegus, ${ }^{2}$ Henok Woldu, ${ }^{3}$ \\ Ephrem Fisseha, ${ }^{4,5}$ Gebremeskel Belai, ${ }^{5}$ Mulugeta Russom (i) 6,7,8
}

\section{ABSTRACT}

Background Multidrug-resistant tuberculosis (MDR-TB) drugs have never been associated with erythrocytosis. In Eritrea, however, several cases of incident erythrocytosis had been observed in the MDR-TB hospital. This study was aimed at exploring the association between MDR-TB drugs and secondary erythrocytosis, characterising the cases, and identifying other possible risk factors.

Methods A retrospective cohort study was conducted in Merhano National Referral MDR-TB hospital. Data were extracted from physically available clinical cards and laboratory results collected longitudinally between 23 June 2011 and 17 January 2021. Initially, univariate descriptive statistics (frequency, mean (SD), median (IQR) and range) were used as appropriate. Then, $\chi^{2}$ or Fisher $\chi^{2}$ test, and bivariate and/or multivariate Cox proportional hazard model were used to identify the predictors of incident erythrocytosis. All statistical analyses were conducted using $\mathrm{R}$, and a two-sided alpha 0.05 was used to determine the statistical significance.

Results A total of 257 patients' medical cards were screened, and 219 were eligible for further analysis. The median age of the patients was 38 years (range: 13-90 years) and $54.8 \%$ were males. During the follow-up time, $31(14.2 \%)$ patients developed secondary erythrocytosis yielding an incidence rate of 7.8 cases per 1000 personmonths. On average, the median time to onset of the event was found to be 5-months (range: 1-24 months). Males were more likely to develop the event than females (adjusted $\mathrm{HR}=7.13,95 \% \mathrm{Cl}=1.66$ to 30.53 ), and as body weight increases by $1 \mathrm{~kg}$, the likelihood of developing secondary erythrocytosis was found to increase by $7 \%$ (adjusted $\mathrm{HR}=1.07,95 \% \mathrm{Cl}=1.03$ to 1.10 ). Moreover, all cases of secondary erythrocytosis were found to be possibly associated with the MDR-TB drugs.

Conclusion The authors hypothesised that the incident erythrocytosis is possibly be associated with MDR-TB drugs, and further studies are required to substantiate this finding.

employer(s)) 2021. Re-use permitted under CC BY-NC. No commercial re-use. See rights and permissions. Published by BMJ.

For numbered affiliations see end of article.

Correspondence to Sirak Tesfamariam; sirakin02015@gmail.com

\section{BACKGROUND}

Multidrug-resistant tuberculosis (MDR-TB) is a disease caused by Mycobacterium tuberculosis strains that are resistant to at least both

\section{Key messages}

The study sought to explore the association between multidrug-resistant tuberculosis (MDR-TB) drugs and secondary erythrocytosis, characterise the cases, and identify other possible risk factors.

- The study found a high incidence of secondary erythrocytosis after the commencement of MDR-TB drugs (Incidence rate: 7.8 cases per 1000 person-months) and according to the Naranjo probability scale, all cases were found to be possibly associated with the MDR-TB drugs. Males were more likely to develop secondary erythrocytosis compared to females and with increasing body weight, the likelihood of developing the event was found to increase.

- We found a previously undocumented association between MDR-TB drugs and erythrocytosis though further studies are required to substantiate the current finding.

rifampicin and isoniazid. ${ }^{1}$ Worldwide, in 2019, there were about half a million new cases of rifampicin-resistant tuberculosis, of which $78 \%$ were MDR-TB. ${ }^{2}$ In Eritrea, 1828 people developed TB in $2019,{ }^{3}$ and according to a nationwide survey conducted in 2018 , the prevalence of rifampicin-resistant tuberculosis was $2.0 \%$ among new cases and $7.5 \%$ among previously treated patients; MDR-TB prevalence was $1.0 \%$ and $3.8 \%$ among new and previously treated cases, respectively. ${ }^{4}$

The treatment regimen for MDR-TB, especially those considered second-line drugs, are known for their significant adverse events and higher toxicity profile. ${ }^{1}$ These drugs can cause adverse effects ranging from minor nausea and vomiting to severe reactions, including organ toxicities. ${ }^{5-7}$ That being said, MDR-TB drugs have never been associated with secondary erythrocytosis.

Erythrocytosis is a haematological disorder characterised by an increased haemoglobin concentration and/or haematocrit in the 
peripheral blood. ${ }^{8}$ It can be primary where there is an intrinsic defect in the bone marrow resulting in increased red-cell production. In contrast, secondary erythrocytosis arises when other conditions drive the production of red blood cells. ${ }^{9}$ Although many conditions can cause secondary erythrocytosis, renal and hepatic diseases, cigarette smoking, hypoxia from chronic lung diseases, obstructive sleep apnoea, testosterone or anabolic steroids, erythropoietin and living at high altitude are the most common risk factors. ${ }^{10-13}$ The prevalence of secondary erythrocytosis is not known in the general population owing to the diversity of causes and paucity of data. However, its prevalence in risk groups ranges from $2 \%$ to $8 \% .^{12}$

Several cases of incident erythrocytosis had been observed in Merhano National Referral MDR-TB hospital, Eritrea, which triggered the authors to conduct this study. The aim of the study, therefore, was to explore the causal association between MDR-TB drugs and secondary erythrocytosis, characterise the cases, and identify other possible risk factors.

\section{METHODS}

\section{Study design and setting}

This was a retrospective cohort study conducted in Merhano National Referral MDR-TB hospital, Eritrea. Historical data were collected from 18-28 January 2021. Merhano National Referral MDR-TB hospital, established in June 2011, is located $12 \mathrm{~km}$ South of Asmara, the capital of Eritrea, at an elevation of $2325 \mathrm{~m}$ above sea level.

\section{Data source}

Data were extracted from physically available clinical cards, patient registers and laboratory results collected longitudinally between 23 June 2011 and 17 January 2021. The laboratory results abstracted consist of haemoglobin and haematocrit levels as well as renal, liver, and thyroid function tests.

\section{Study population}

The study evaluated clinical records of all patients admitted to MDR-TB hospital for treatment between June 2011 and January 2021. Patients with baseline haemoglobin or haematocrit level greater than the diagnostic reference range and patients without a second follow-up laboratory measurement results were excluded from the study.

\section{Patient and public involvement}

Due to the retrospective nature of the study, patients and/ or public were not involved in designing, conducting, reporting or disseminating of this research.
Exposure and outcome definition

The primary outcome of interest was the development of secondary erythrocytosis following the commencement of MDR-TB drugs. Secondary erythrocytosis is defined as a haematological disorder characterised by an increased haemoglobin concentration and/or haematocrit in the peripheral blood arising when conditions other than intrinsic defect of the bone marrow drive the production of red blood cells. ${ }^{89}$ The diagnostic criterion used was haemoglobin level greater than $17.6 \mathrm{~g} / \mathrm{dL}$ in females and $17.8 \mathrm{~g} / \mathrm{dL}$ in males, and/or haematocrit level greater than $52 \%$ in females and $55 \%$ in males. ${ }^{14}$

\section{Data collection tool}

A structured questionnaire was adopted from the one developed by the Eritrean Pharmacovigilance Centre for documenting the adverse effects of MDR-TB drugs. The questionnaire consists of sociodemographic characteristics, adverse reaction details, drug details, baseline data and laboratory follow-ups. Following a pretest of the questionnaire, a 1-day orientation was given to the data collectors.

\section{Causality assessment}

Whether the encountered secondary erythrocytosis was related to the MDR-TB drugs or not, it was assessed using Naranjo adverse drug reaction probability scale. ${ }^{15}$ The causality assessment was made by three experienced researchers (a physician, a pharmacist and a pharmacovigilance expert) and a decision was made following the group consensus.

\section{Labelledness}

The primary reference materials used for assessing the documentation of the adverse event, secondary erythrocytosis, were the summary of product characteristics of the MDR-TB drugs approved by the stringent regulatory authorities. Moreover, online databases such as Martindale complete drug reference, SIDER, Micromedex, and search engines such as PubMed/Medline and Google scholar were explored.

\section{Statistical analysis}

As a preliminary step, univariate descriptive statistics were used to present simple table frequency of all the categorical variables, and mean (SD), median (IQR) and range for the continuous variables by cohort group (secondary erythrocytosis vs no secondary erythrocytosis) were reported as appropriate. Initial confirmatory analyses were conducted using the $\chi^{2}$ test to assess the association between the study outcome variable (secondary erythrocytosis) and all the covariates. Whenever the expected frequency was found to be less than $5 \%$, Fisher $\chi^{2}$ test was used. All variables found to be significant in the $\chi^{2}$ analysis were used in the bivariate and/or multivariate Cox proportional hazard model. Both bivariate 


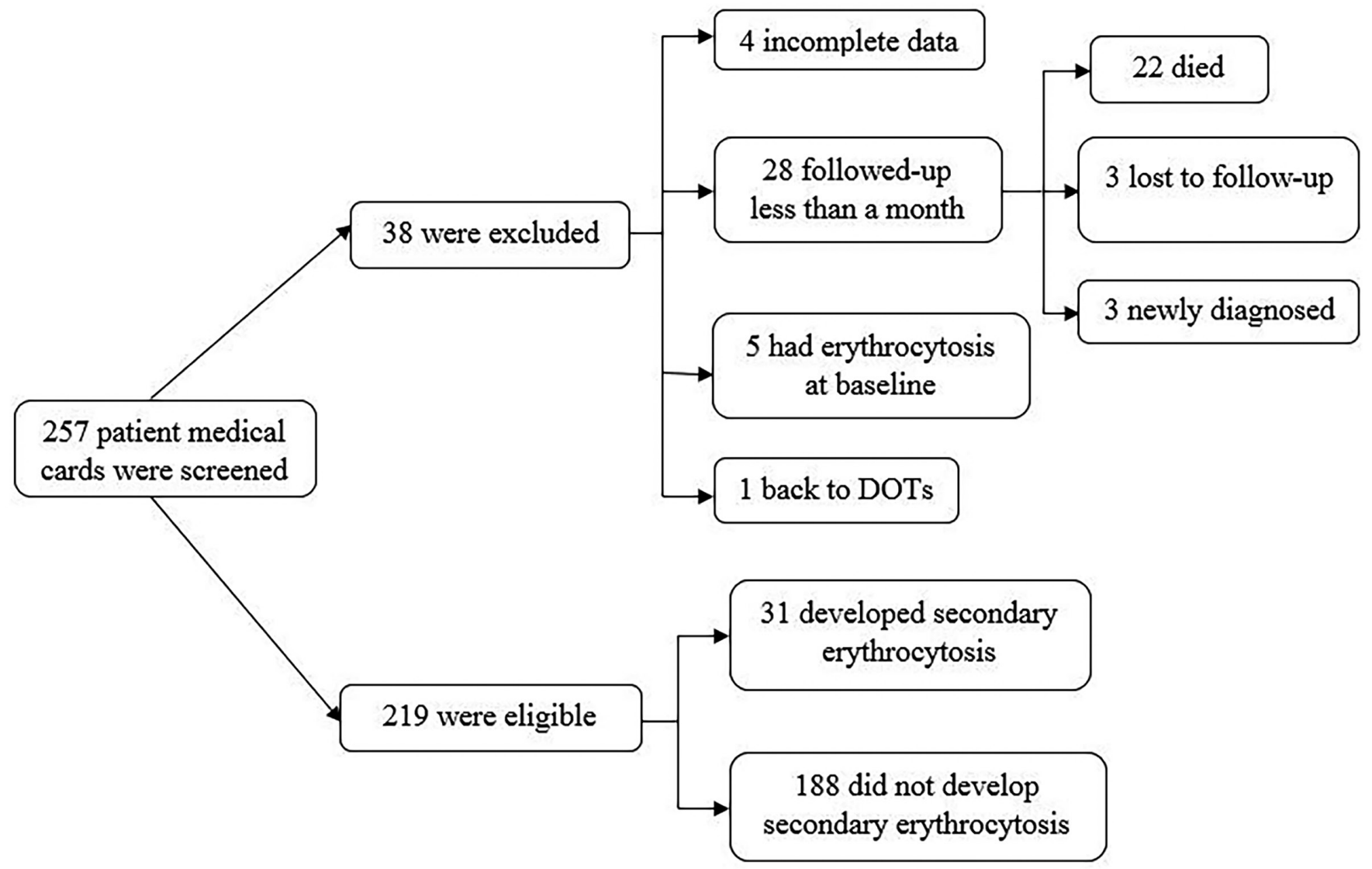

Figure 1 Summary of the study's patient cards enrolment. DOTs, directly observed treatment, short-course.

and multivariate Cox proportional hazard models were used to identify the predictors of incident erythrocytosis. Assumption related to Cox proportional hazard models was tested using a graphical method of log-log plot and was found to be not violated. For all statistical tests, a twosided alpha 0.05 significance level was used to determine the statistical significance. All statistical analyses for this study were conducted using R. ${ }^{16}$

\section{RESULTS}

A total of 257 patient medical cards were screened, and 219 were eligible for further analysis. From the total reviewed patient cards, 38 medical cards were excluded due to follow-up durations of less than a month $(n=28)$, incomplete data $(n=4)$, blood parameter with erythrocytosis at baseline $(n=5)$ and a patient who got back to firstline treatment $(\mathrm{n}=1)$. A patient medical card with missing data on any essential laboratory result was considered incomplete. The flow chart of the study patients' enrolment is depicted in figure 1.

Patients enrolled in this study were $54.8 \%$ males and mainly aged below 56 years $(80.8 \%)$. The age of the patients ranges from 13 to 90 years (median=38 years, $\mathrm{IQR}=23$ years). Approximately one-third of the patients were residents of Asmara which has the same altitude as the MDR-TB hospital, and $60.5 \%$ of the patients were residing in different places with an altitude higher than
$1500 \mathrm{~m}$ above sea level. Except 10 (4.6\%), all the patients were diagnosed with pulmonary $\mathrm{TB}$ and $83.5 \%$ had no comorbidities. HIV infection $(10 \%)$, diabetes mellitus $(5 \%)$, psychiatric illness $(0.9 \%)$, asthma $(0.5 \%)$ and chronic kidney diseases $(0.5 \%)$ were the mentioned comorbid conditions. The detailed sociodemographic and clinical characteristics of the study participants are displayed in table 1.

During the MDR-TB treatment and follow-up period, $64(29.2 \%)$ patients developed liver injury, $20(9.1 \%)$ renal injury and $130(59.4 \%)$ hypothyroidism. Almost $70 \%$ of the patients completed the treatment successfully, $7.8 \%$ died, $6.4 \%$ were lost to follow-up, while $16 \%$ were still under treatment at the time of the study.

The average follow-up time was 2-years and during this follow-up time, $31(14.2 \%)$ patients developed secondary erythrocytosis yielding an incidence rate of 7.8 cases per 1000 person-months. The median time to onset of the incident erythrocytosis was found to be 5-months (range: 1-24 months), where 20 patients developed the event within 6-months after the initiation of the drugs. Phlebotomy was reported as action taken to manage the condition in two cases. In rest of the cases, either no action was taken or unknown. The clinical and sociodemographic characteristics of the patients who developed secondary erythrocytosis are attached as online supplemental file 1 . 
Table 1 Sociodemographic and clinical characteristics of patient with MDR-TB by secondary erythrocytosis status who attended Merhano national referral MDR-TB Hospital, Eritrea from June 2011 to January 2021

\begin{tabular}{|c|c|c|c|c|}
\hline \multirow[b]{2}{*}{ Variables } & \multicolumn{2}{|l|}{ Cohort group } & \multirow[b]{2}{*}{ Total } & \multirow[b]{2}{*}{$P$ value } \\
\hline & Erythrocytosis & No erythrocytosis & & \\
\hline Total number of patients & 31 & 188 & 219 & \\
\hline \multicolumn{5}{|c|}{ Age (years) median (IQR): 38 (23), range $=13-90$} \\
\hline 35 and below & 16 & 73 & 89 & \multirow[t]{3}{*}{0.366} \\
\hline $36-55$ & 11 & 77 & 88 & \\
\hline 56 and above & 4 & 38 & 42 & \\
\hline \multicolumn{5}{|l|}{ Sex } \\
\hline Male & 29 & 91 & 120 & \multirow[t]{2}{*}{$<0.001$} \\
\hline Female & 2 & 97 & 99 & \\
\hline \multicolumn{5}{|l|}{ Baseline body weight (kgs) } \\
\hline$<33$ & 1 & 23 & 24 & \multirow[t]{4}{*}{$<0.001^{*}$} \\
\hline $33-50$ & 13 & 136 & 149 & \\
\hline $51-70$ & 15 & 25 & 40 & \\
\hline$>70$ & 2 & 3 & 5 & \\
\hline \multicolumn{5}{|l|}{ Educational status } \\
\hline No formal education & 2 & 53 & 55 & \multirow[t]{5}{*}{$0.027^{\star}$} \\
\hline Primary & 4 & 28 & 32 & \\
\hline Middle & 14 & 54 & 68 & \\
\hline Secondary & 8 & 45 & 53 & \\
\hline Higher education & 3 & 7 & 10 & \\
\hline \multicolumn{5}{|l|}{ Residence } \\
\hline Asmara & 13 & 56 & 69 & \multirow[t]{2}{*}{0.271} \\
\hline Other than Asmara & 18 & 130 & 148 & \\
\hline \multicolumn{5}{|l|}{ Altitude (metres) } \\
\hline Below 750 & 2 & 32 & 34 & \multirow[t]{3}{*}{$0.249^{*}$} \\
\hline $750-1500$ & 5 & 32 & 37 & \\
\hline Above 1500 & 21 & 99 & 120 & \\
\hline \multicolumn{5}{|l|}{ Comorbidity } \\
\hline Yes & 6 & 30 & 36 & \multirow[t]{2}{*}{0.842} \\
\hline No & 25 & 157 & 182 & \\
\hline \multicolumn{5}{|l|}{ Liver injury } \\
\hline Yes & 11 & 53 & 64 & \multirow[t]{2}{*}{0.536} \\
\hline No & 19 & 129 & 148 & \\
\hline \multicolumn{5}{|l|}{ Renal injury } \\
\hline Yes & 5 & 15 & 20 & \multirow[t]{2}{*}{$0.163^{*}$} \\
\hline No & 24 & 168 & 192 & \\
\hline \multicolumn{5}{|l|}{ Hypothyroidism } \\
\hline Yes & 17 & 113 & 130 & \multirow[t]{2}{*}{0.906} \\
\hline No & 12 & 70 & 82 & \\
\hline \multicolumn{5}{|l|}{ Treatment duration (months) } \\
\hline Less than or equal to 6 & 20 & 15 & 35 & $<0.001^{*}$ \\
\hline $7-12$ & 4 & 22 & 26 & \\
\hline Greater than 12 & 7 & 151 & 158 & \\
\hline
\end{tabular}

${ }^{*}$ Fisher $\chi^{2}$ test 
Table 2 Bivariate and multivariate COX proportional hazard model to determine factors associated with incidence of secondary erythrocytosis among patients who attended Merhano national referral MDR-TB Hospital, Eritrea from June 2011 to January 2021

\begin{tabular}{|c|c|c|c|c|}
\hline Variables & HR $(95 \% \mathrm{Cl})$ & $P$ value & Adjusted HR (95\% Cl) & $P$ value \\
\hline \multicolumn{5}{|l|}{ Sex } \\
\hline Male & 13.84 (3.30 to 58.03$)$ & $<0.001$ & 7.13 (1.66 to 30.53$)$ & 0.008 \\
\hline \multicolumn{5}{|l|}{ Educational Status } \\
\hline Primary & $3.54(0.65$ to 19.34$)$ & 0.144 & & \\
\hline Secondary & 4.31 (0.91 to 20.29$)$ & 0.064 & & \\
\hline Higher education & 8.71 (1.46 to 52.19$)$ & 0.018 & & \\
\hline No formal education & Ref & & & \\
\hline Baseline body weight & 1.09 (1.05 to 1.12$)$ & $<0.001$ & 1.07 (1.03 to 1.10$)$ & $<0.001$ \\
\hline Altitude & $1.00(0.99$ to 1.01$)$ & 0.079 & & \\
\hline
\end{tabular}

Ref, reference.

To find the possible association between the sociodemographic or medical characteristics, and the development of secondary erythrocytosis, a $\chi^{2}$ or Fisher $\chi^{2}$ test was done as appropriate. Among the tested variables, sex $(p<0.001)$, baseline body weight $(p<0.001)$, educational level $(p=0.027)$ and duration of treatment $(p<0.001)$ were found to be associated with the development of secondary erythrocytosis. After running bivariate and multivariate Cox proportional hazard model to determine the magnitude of the influence/association (table 2), males were almost seven times (adjusted HR=7.13, 95\% CI $=1.66$ to 30.53) more likely to develop secondary erythrocytosis than females. Additionally, as the baseline body weight of the patients increases by $1 \mathrm{~kg}$, it was found that the likelihood of developing secondary erythrocytosis increases by $7 \%$ (adjusted $\mathrm{HR}=1.07,95 \% \mathrm{CI}=1.03$ to 1.10 ). At the multivariate level, educational status was found to be insignificant.

According to Naranjo probability scale, all the secondary erythrocytosis cases were found to be possibly associated with the MDR-TB drugs.

\section{DISCUSSION}

The current study found a relatively high incidence of erythrocytosis following the use of MDR-TB drugs though its prevalence among risk groups is low $(2 \%-8 \%) .{ }^{12}$ This suggests that there is a triggering factor(s) that could possibly expose patients to incident erythrocytosis. Thorough literature search on PubMed/Medline and Google Scholar shows that the MDR-TB drugs used (kanamycin and/or capreomycin, levofloxacin, ethionamide, cycloserine, para-aminosalicylic acid or pyrazinamide), vitamin $\mathrm{B}_{6}$ and MDR-TB itself have never been associated with erythrocytosis.

Secondary erythrocytosis can occur as a result of altitude changes, heavy smoking, massive obesity, use of steroids, comorbidities (including renal or liver injury) and chronic pulmonary diseases. ${ }^{11-13} 17$ Accordingly, in the current study, the contribution of other drugs taken, altitude of residence, availability of other diseases/conditions and other possible risk factors of secondary erythrocytosis were ruled-out systematically. Results showed that none of these factors had statistically significant associations with incident erythrocytosis. Although chronic pulmonary diseases have been associated with a rise in haemoglobin level, ${ }^{9}{ }^{18}$ we could not find any evidence that suggests tuberculosis as a risk factor of erythrocytosis.

Several patients who had developed hypothyroidism were taking levothyroxine. There were also two patients living with HIV who had taken a combination of efavirenz, emtricitabine and tenofovir disoproxil fumarate and another two diabetic patients-one on insulin-based therapy and the other taking metformin and glibenclamide. However, none of the summary of product characteristics of the aforementioned products state secondary erythrocytosis as an adverse effect. ${ }^{19-32}$ On the contrary, anaemia has been reported as an adverse effect of levofloxacin, pyrazinamide, emtricitabine and para-aminosalicylic acid. ${ }^{212425} 28$ Though erythrocytosis is reported slightly higher in males compared with females in some populations, ${ }^{33}{ }^{34}$ it is unknown why males were considerably exposed $(93.5 \%)$ to secondary erythrocytosis in this study.

Though the association is poorly documented, diet and supplementary intake could contribute to the development of secondary erythrocytosis. For a number of reasons, diet and use of supplements is strictly controlled during the intensive treatment phase (first 6-months). As per the hospital registry, supplements such as multivitamin, folic acid and calcium can be given according to a patient condition. However, none of the cases who developed secondary erythrocytosis had taken any supplement during this period. Additionally, the routine diet schedule of the hospital is egg and milk (daily); meat (four times 
weekly); rice, vegetables, and lentils (at least twice weekly each) and a strong association of these food types with the development of erythrocytosis could not be found.

Both MDR-TB and MDR-TB drugs could be associated with the development of erythrocytosis. However, about $22.5 \%$ of the cases developed the condition after 1-year of starting treatment where at this stage the disease is at its recovery and is less likely to lead to such complications. This supports the fact that the outcome of interest could possibly be associated with the MDR-TB drugs though the contribution of MDR-TB could not be completely ruled out. Findings of the study can be clinically important as erythrocytosis might increase the risk of cardiovascular events such as thromboembolism, haemorrhage, stroke, and myocardial infarction. ${ }^{10} 1335$

Although, to our knowledge, this study described a previously undocumented association between MDR-TB drugs and erythrocytosis, it had the following limitations. Due to the retrospective nature of the study, results of diagnostic tests such as bone marrow aspiration, CT scan, spirometry, polysomnography and other important parameters to validate diagnoses could not be retrieved. Thus, some conditions that might cause erythrocytosis, such as obstructive sleep apnoea and polycythemia vera, could not be ruled out. Moreover, the fact that the MDR-TB drugs were administered at the same time and information on dechallenge and rechallenge was unavailable, the authors could not attribute the event to a specific drug.

\section{CONCLUSION}

Taking all the above factors into consideration, the authors hypothesised that the incident erythrocytosis is possibly associated with MDR-TB drugs. Therefore, further studies are required to substantiate the current findings as the results could be important for risk mitigation, management, and patient monitoring.

\section{Author affiliations}

${ }^{1}$ Product Evaluation and Registration Unit, National Medicines and Food Administration, Asmara, Eritrea

${ }^{2}$ Hazhaz Zonal Referral Hospital, Asmara, Eritrea

${ }^{3}$ The Center for Health Analytics for National and Global Equity (C.H.A.N.G.E), Columbia, Missouri, USA

${ }^{4}$ Eritrean Air-Force Military Hospital, Asmara, Eritrea

${ }^{5}$ Merhano National Referral MDR-TB Hospital, Asmara, Eritrea

${ }^{6}$ Eritrean Pharmacovigilance Center, National Medicines and Food

Administration, Asmara, Eritrea

${ }^{7}$ Department of Medical Informatics, Erasmus Medical Center, Rotterdam, Netherlands

${ }^{8}$ European Programme for Pharmacovigilance and Pharmacoepidemiology, University of Bordeaux, Bordeaux, France

Acknowledgements The authors would like to sincerely thank the staff of the communicable disease control division, Ministry of Health of Eritrea, for their invaluable comments.

Contributors MR conceived the idea and is the guarantor of the study. All authors designed, conducted and interpreted the results of the study. Data were collected by ASG, GB and ST, and analysed by HW. ASG, MR and ST drafted the manuscript, and EF critically reviewed it. Finally, the manuscript was approved by all authors.
Funding The authors have not declared a specific grant for this research from any funding agency in the public, commercial or not-for-profit sectors.

Competing interests None declared.

\section{Patient consent for publication Not applicable.}

Ethics approval Ethical approval was obtained from the Health Research Ethics and Protocol Review Committee of the Ministry of Health (Reference no. 06/03/17). All ethical and professional considerations were followed throughout the study to keep patient records strictly confidential and patients' identifiers were anonymised and deidentified prior to analysis. As this was a retrospective study, informed consent was not obtained from patients and waived by the committee.

Provenance and peer review Not commissioned; externally peer reviewed.

Data availability statement No additional data is available.

Supplemental material This content has been supplied by the author(s). It has not been vetted by BMJ Publishing Group Limited (BMJ) and may not have been peer-reviewed. Any opinions or recommendations discussed are solely those of the author(s) and are not endorsed by BMJ. BMJ disclaims all liability and responsibility arising from any reliance placed on the content. Where the content includes any translated material, BMJ does not warrant the accuracy and reliability of the translations (including but not limited to local regulations, clinical guidelines, terminology, drug names and drug dosages), and is not responsible for any error and/or omissions arising from translation and adaptation or otherwise.

Open access This is an open access article distributed in accordance with the Creative Commons Attribution Non Commercial (CC BY-NC 4.0) license, which permits others to distribute, remix, adapt, build upon this work non-commercially, and license their derivative works on different terms, provided the original work is properly cited, appropriate credit is given, any changes made indicated, and the use is non-commercial. See: http://creativecommons.org/licenses/by-nc/4.0/.

\section{ORCID iDs}

Sirak Tesfamariam http://orcid.org/0000-0003-4348-5952

Mulugeta Russom http://orcid.org/0000-0003-1939-5842

\section{REFERENCES}

1 World Health Organization. WHO consolidated guidelines on tuberculosis: module 4: treatment: drug-resistant tuberculosis treatment. World Health Organization, 2020.

2 World Health Organization. Global tuberculosis report 2020, 2020.

3 World Health organization TB country, regional and global profiles: Eritrea, 2020. Available: https://worldhealthorg.shinyapps.io/tb_ profiles/?_inputs_\&entity_type="country"\&lan="EN"\&iso2="ER" [Accessed 23 Jul 2021].

4 Mesfin AB, Araia ZZ, Beyene HN, et al. First molecular-based anti-TB drug resistance survey in Eritrea. Int $J$ Tuberc Lung Dis 2021;25:43-51.

5 Bhardwaj P, Deshkar AM, Verma R. Side effects encountered in treatment of multidrug-resistant tuberculosis: a 3-year experience at first dots plus site of Chhattisgarh. International Journal of Scientific Study 2015;3:104-7.

6 Tag EI Din MA, El Maraghy AA, Abdel Hay AHR. Adverse reactions among patients being treated for multi-drug resistant tuberculosis at Abbassia chest Hospital. Egypt J Chest Dis Tuberc 2015;64:939-52.

7 Russom Met al. Nature, magnitude and risk factors of adverse drug reactions in multidrug resistant TB patients in Eritrea. Eur Respiratory Soc 2018.

8 Tefferi A. Diagnostic approach to the patient with polycythemia. UpToDate, 2013.

9 McMullin MF. Diagnosis and management of congenital and idiopathic erythrocytosis. Ther Adv Hematol 2012;3:391-8.

10 McMullin MF, Harrison CN, Ali S, et al. A guideline for the diagnosis and management of polycythaemia vera. A British Society for haematology guideline. Br J Haematol 2019;184:176-91.

11 Keohane C, McMullin MF, Harrison C. The diagnosis and management of erythrocytosis. BMJ 2013;347:f6667.

12 Mithoowani S, Laureano M, Crowther MA, et al. Investigation and management of erythrocytosis. Can Med Assoc J 2020;192:E913-8.

13 Haider MZ, Anwer F. Secondary polycythemia. StatPearls, 2020.

14 Siraj N, Issac J, Anwar M, et al. Establishment of hematological reference intervals for healthy adults in Asmara. BMC Res Notes 2018;11:1-6.

15 Naranjo Cet al. Naranjo ADR probability scale. Clin Pharmacol Ther 1981;30:239-45.

16 Team, R.C. R: a language and environment for statistical computing, 2013. 
17 Spivak JL. Polycythemia vera. Curr Treat Options Oncol 2018;19:1-14.

18 Kent BD, Mitchell PD, McNicholas WT. Hypoxemia in patients with COPD: cause, effects, and disease progression. Int J Chron Obstruct Pulmon Dis 2011;6:199.

19 Kanamycin summary product characteristics. Available: https:// extranet.who.int/pqweb/sites/default/files/TB301 part4v1.pdf

20 Capreomycin summary product characteristics. Available: http:// www.ndda.kz/upload/dari.kz/Vnesenie\%20izmeneni/SPC\% 20Capreomycin.pdf

21 Levofloxacin summary product characteristics. Available: https:// www.medicines.org.uk/emc/product/4625/smpc\#gref

22 Ethionamide summary product characteristics. Available: https:// extranet.who.int/pqweb/sites/default/files/TB207part4_1.pdf

23 Cycloserine summary product characteristics. Available: https:// extranet.who.int/pqweb/sites/default/files/TB236part4v1.pdf

24 Para-amino salicylic acid summary product characteristics. Available: https://www.ema.europa.eu/en/documents/productinformation/granupas-epar-product-information_en.pdf

25 Pyrazinamide summary product characteristics. Available: https:// extranet.who.int/pqweb/sites/default/files/TB159part4.pdf

26 Pyridoxine summary product characteristics. Available: https://www. medicines.org.uk/emc/product/1208/smpc\#gre

27 Levothyroxine summary product characteristics. Available: https:// www.medicines.org.uk/emc/product/5682/smpc\#gre
28 Efavirez/Emtricitabine/Tenofovir disoproxil fumarate summary product characteristics. Available: https://extranet.who.int/pqweb/ sites/default/files/HA444part4.pdf

29 Insulin Glargine summary product characteristics. Available: https:// www.ema.europa.eu/en/documents/product-information/insulinlispro-sanofi-epar-product-information_en.pdf

30 Insulin lispro summary product characteristics. Available: https:// www.ema.europa.eu/en/documents/product-information/lantusepar-product-information_en.pdf

31 Metformin summary product characteristics. Available: https://www. medicines.org.uk/emc/product/10759/smpc\#gref

32 Glibenclamide summary product characteristics. Available: https:// www.hpra.ie/img/uploaded/swedocuments/LicenseSPC_PA0688040-002_07092016112043.pdf

33 Moulard O, Mehta J, Fryzek J, et al. Epidemiology of myelofibrosis, essential thrombocythemia, and polycythemia vera in the European Union. Eur J Haematol 2014;92:289-97.

34 Kremyanskaya M, Mascarenhas J, Hoffman R. Why does my patient have erythrocytosis? Hematol Oncol Clin North Am 2012;26:267-83.

35 Wouters HJCM, Mulder R, van Zeventer IA, et al. Erythrocytosis in the general population: clinical characteristics and association with clonal hematopoiesis. Blood Adv 2020;4:6353-63. 